\title{
The Cavendish Laboratory, Cambridge
}

\section{Benefaction by Sir Herbert Austin, K.B.E.}

$\mathrm{T}$ $\mathrm{HE}$ benefaction of approximately $£ 250,000$ by Sir Herbert Austin for the future work of the Cavendish Laboratory satisfies in a most handsome way one of the urgent needs of the University of Cambridge.

In recent years, developments in physics have changed the requirements of experimental physicists from the glass tube and electrometer of an earlier generation to apparatus such as the two million volt generator, the 50-ton magnet or the cryogenic laboratory. The initiation in Cambridge of new fields of work involving such apparatus has been made possible by the support of the Department of Scientific and Industrial Research, by generous help from the Royal Society and by special grants from the University. Inevitably, however, it would have been difficult for the University to provide from its limited resources for a continuation of such developments in the future, and for some time the need of research endowment has been strongly felt.

Not only have funds been required for research purposes, but also far-reaching reconstructions of the buildings of the Laboratory have also become necessary. The oldest wing of the Cavendish Laboratory was built under the close personal supervision of Clerk Maxwell between 1871 and 1874, the cost being defrayed by the seventh Duke of Devonshire, then Chancellor of the University. The Laboratory, built in a restrained Gothic manner, consisted of a large lecture room, ground floor research rooms and workshop, and class rooms above. In this building Maxwell, Rayleigh and J. J. Thomson built up the Cambridge school of experimental physics. Between the years 1877 and 1893, the number of students rose from 22 to 150 , and in 1893 the first extension of the Laboratory was made, houses in Free School Lane being converted into a large class room for elementary teaching with a small lecture room and offices above. In 1896, with the admission of graduates of other universities to carry out research work with J. J. Thomson, the number of research workers gradually increased, and by 1906 further extensions became necessary. For this Lord Rayleigh generously handed over the sum of $£ 5,000$, being the greater part of his Nobel Prize, and by 1908 the ground floor research rooms known as the 'Garage', the lecture room above and the small block of research rooms on the second floor had been completed.

During the directorship of Lord Rutherford, the number of research workers in the Laboratory increased further to between forty and fifty, and to provide for this and for the increasing scale of the work, further accommodation became urgently necessary. Fortunately for the development of the work, the great Rockefeller benefaction of 1930 enabled the University to provide new accommodation for the biological departments, and to hand over some of the old buildings adjoining the Cavendish Laboratory until such time as they could be reconstructed.

Plans were then prepared showing how the site could best be used, and the organisation of an appeal for the sum of $£ 250,000$ was commenced. Much interest has been shown by many friends of the Cavendish. They will be delighted to hear of this splendid gift by Sir Herbert Austin.

The University, in the confident expectation that the appeal would succeed, had already authorised the construction of a new high-voltage laboratory. It will now be possible to prepare a more far-reaching scheme including a new research block on the site of the old Zoological Laboratory, and some reorganisation of the teaching wing. It should also be possible to meet many long-felt needs of the Laboratory, and to provide substantially increased facilities for research.

We have received the following appreciative notice of the work of the Cavendish Laboratory from Sir Ambrose Fleming :

IN common with all other Cambridge men, I am enormously gratified to hear of the splendid munificence of Sir Herbert Austin in giving a quarter of a million sterling to the University of Cambridge for the special benefit of the Cavendish Laboratory.

That Laboratory and chair of physics was founded in $\mathbf{1 8 7 0}$ by the generosity of the seventh Duke of Devonshire, then Chancellor of the University, and the first occupant of the chair was James Clerk Maxwell whose contributions to science had made him then of world-wide fame. Under him the Laboratory was designed and equipped. Among a small number of his first students I had the privilege of being numbered. This group included the late Principal W. M. Hicks, Sir Richard Glazebrook, Mr. J. E. H. Gordon, Prof. G. Chrystal, Sir Arthur Schuster and Prof. J. H. Poynting, with William Garnett as 
demonstrator. My own work there consisted, at Maxwell's suggestion, in comparing the existing B.A. standards of resistance with the object of ascertaining the most probable value of the B.A. unit, the absolute value of which was afterwards determined by the work of Lord Rayleigh and Sir Arthur Schuster. For this purpose a special form of resistance balance was designed which was in use for many years afterwards at the Cavendish Laboratory.

After the lamented decease of Prof. Clerk Maxwell in 1879, Lord Rayleigh consented to hold the chair for a time in response to a universal request, and made in a few years most notable contributions to exact electrical measurement.

Then on Lord Rayleigh's retirement, Sir J. J. Thomson, now Master of Trinity College, was appointed, and began his epoch-making researches on the constitution of the atom. Under him a large number of research workers were gathered whose discoveries made the Cavendish Laboratory world-famous.

On Thomson's retirement, Lord Rutherford succeeded to the chair, and his great discoveries in radioactive matter and the structure of the atom have opened new chapters in the history of science.
With him have been associated other workers whose researches have given them fame. The work of Dr. Aston on isotopes and the discovery of the neutron by Prof. James Chadwick, and more recent work by others, such as Drs. J. D. Cockcroft and E. T. S. Walton, have made departures of an importance not easily overstated.

This donation of Sir Herbert Austin will, I believe, be devoted to the erection and equipment of a new high-voltage laboratory, where electromotive forces of a million or more volts will be employed to hurl the hardest particles in nature, namely the alpha particle, at other atoms, and so break up their nuclei. It is possible by some such process that an artificial radium may be produced with all the valuable properties of the natural radium in therapeutic work. It is impossible yet to foresee all the supreme importance of the outcome of such a new laboratory. We know already that enormous stores of atomic energy are awaiting discovery and utilisation, and this great benefaction of Sir Herbert Austin when utilised by the resourceful and able research workers in physics at Cambridge will unquestionably bring in due course not only greater knowledge but also greater benefits to mankind.

\section{Blackpool Meeting of the British Association}

$\mathrm{T}$ HE visits of the British Association to Lancashire have not been infrequent-they began with the Liverpool visit of 1837-and its members know, and appreciate, the traditions of Lancashire hospitality. In its history of a hundred and five years the Association has visited Liverpool six times, Manchester thrice and Southport twice. Now the Association will enlarge its experiences, having accepted for this year (September 9-16) the invitation extended by the Mayor and Corporation of the Borough of Blackpool.

Each of the great cities of the North has its special characteristics, but their civic and industrial activities may be matched in other regions. Blackpool may fairly be said to be unique. It has devoted itself to the problems of the systematisation of mass-amusements with a spaciousness which is all its own. In these, and in its municipal activities, it has preserved a pioneering energy and ability to take the long view given to it by the farsightedness of its first Mayor, the late Dr. W. H. Cocker-an ability which has made Blackpool's remarkable experiments in town lighting and traction models for other communities for more than fifty years past. The Blackpool meeting also affords special opportunities for the study of what is, in its integrity, a little-known corner of the kingdom. The Fylde is a division of England the natural features of which will well repay investigation, a division which still has its own peculiarities of thought and diction and the villages of which preserve something of the atmosphere of those days when the Industrial Revolution was not.

Sir Josiah Stamp will deliver his presidential address in the Empress Hall of the Winter Gardens. The exact title of the address is not announced, but it will deal with the impact of science on society-a subject at once arresting and topical. The spirit of the age is less and less in sympathy with the view that science may be pursued regardless of its repercussions on the community; nor, in these times, may we be quite so complacent concerning the benefits conferred by science on society as was the fashion in the days of Samuel Smiles. Eugenic and dysgenic effects must be considered, and those who look to Sir Josiah Stamp for an analysis of these repercussions which shall be critical, far-reaching and provocative, are not likely to be disappointed.

The sectional presidential addresses cover a wide field, and in many instances deal directly with the bearing of scientific investigation on the 